\title{
DIFFERENCES IN TOTAL FACTOR PRODUCTIVITY GROWTH IN THE EUROPEAN UNION: THE ROLE OF HUMAN CAPITAL BY INCOME LEVEL
}

\author{
Sara Barcenilla, Gregorio Gimenez, Carmen López-Pueyo*
}

\begin{abstract}
This article applies Oaxaca-Blinder and Shorrocks-Shapley decomposition techniques to a logistic diffusion model in order to explain the differences in Total Factor Productivity Growth (TFPG) in European Union (EU) countries for the period 1950-2011. Human capital has a dual positive effect on TFPG by boosting innovation and increasing the catch-up capacity of countries to absorb and imitate foreign technologies. Our results show that there are statistically significant differences in the intensity of these effects between high and low average income EU countries, while there are not between euro and non-euro countries. The mean difference in technical change between high and low-income EU countries is largely the result of three factors. The first is the higher average foreign technology assimilation capacity of low income countries. This is particularly true because they are further from the technological frontier and are able to benefit from the advantage of backwardness. The second is the higher direct effect of human capital on technical change in these countries, while the third factor is the higher slowdown role of proximity in them.
\end{abstract}

Keywords: human capital, total factor productivity growth, technological diffusion JEL Classification: $\mathrm{O} 33$

\section{Introduction}

The study of the determinants of technological change has been a central topic in economic growth literature in recent years. The work of Benhabib and Spiegel (1994) was the first to recognise the dual role of human capital in promoting such change: human capital enters as a direct factor in the knowledge production function to promote innovation, while an indirect effect through imitation (or technological diffusion) reflects the catch-up capacity of the country and is measured by the interaction of human capital with distance to the frontier.

An important advance in this line of research was the paper by Benhabib and Spiegel (2005), which demonstrated the superiority of the logistic versus the exponential specification of the technology diffusion process. The new framework introduces the possibility of economic divergence when some factors, such as barriers to entry or

* Sara Barcenilla, Faculty of Economics and Business, University of Zaragoza, Spain (sbarceni@) unizar.es);

Gregorio Gimenez, Faculty of Economics and Business, University of Zaragoza, Spain (gregim@ unizar.es);

Carmen López-Pueyo, Faculty of Economics and Business, University of Zaragoza, Spain (clopez@) unizar.es). 
other difficulties in adopting foreign technologies, moderate the rate of technological diffusion between the leader and the followers. The sign and intensity of these impacts of human capital on growth have generated an intense debate in recent years, see, for example, Vandenbusshe, Aghion and Meghir (2006), Manca (2011), Cerina and Manca (2012), López-Pueyo et al. (2017) and Barcenilla and López-Pueyo (2018). In essence, these studies try to analyse the differential impact that different kinds of human capital (skilled versus unskilled) have on different paths to growth (innovation versus imitation) in countries at different stages of development.

While much of the literature related to this topic has analysed the case of developed versus developing countries, our study examines this research line in the context of the European Union (EU). We want to explain the differences in the generation of new knowledge we observe between different groups of countries within the EU. Initially, using the instrumental variables estimators for panel data models, we estimate two logistic diffusion models to explain TFPG as a function of two factors: human capital and catch-up capacity. Firstly, we distinguish between euro and non-euro area countries and, secondly, we duplicate this model for a sample of lower average income countries (LAIC) versus higher average income countries (HAIC). The results offer an interesting insight by showing that differences between euro and non-euro area countries in boosting technological change are not significant, while those between LAIC and HAIC are.

To study more deeply the differences in the dynamics of technical change between the groups of countries cited above, we apply the Shorrocks-Shapley decomposition and determine the relative contribution of each factor. Our analysis concludes that catch-up capacity explains more than two-thirds of the fit of the model, and is more important for euro than for non-euro countries and for HAIC than for LAIC. In a second phase, we apply the decomposition method of Oaxaca and Blinder to explain the gap in the means of technical change between LAIC and HAIC. The gap is decomposed into that part which is due to group differences in the magnitudes of the input endowments and that one which has its origin in differential returns or the effects of these endowments on technical change. The analysis allows us to reach two main conclusions: the differential effects or returns of the endowments are more powerful than those observed in the magnitude of the inputs or endowments in explaining the gap in technical change. Furthermore, the magnitude and returns of catch-up capacity are much more important factors than the magnitude and the effect of human capital alone in the explanation of the output gap.

The rest of the paper is organized as follows. In Section 2 we present the analytical framework. In Section 3 we describe the model, the variables and the results of the econometric estimation. Section 4 centres on the Shorrocks-Shapley and the Oaxaca-Blinder decompositions. The study ends with the presentation of our conclusions in Section 5.

\section{The Model}

We follow Ha and Howitt (2007) and start from the central hypothesis, common to different versions of endogenous growth models, that the explanatory role of TFPG is equivalent to the knowledge creation function and that both depend on human capital input. In the first 
place, following Romer (1998), human capital is included as an input in the knowledge production function, which represents innovation. Secondly, in line with Nelson and Phelps (1966), the model includes an interaction term between human capital and the distance to the frontier considering the effect human capital on TFPG as a catalyst of absorptive capacity or imitation. This will be greater the further the country is from the frontier.

This effect was modelled for the first time by Benhabib and Spiegel (1994). They chose an exponential diffusion function in which the first term represents the effect of human capital on innovation and the second one the effect on imitation:

$$
\frac{\dot{A}_{i}(t)}{A_{i}(t)}=g\left(H_{i}(t)\right)+c\left(H_{i}(t)\right)\left(\frac{A_{m}(t)}{A_{i}(t)}-1\right),
$$

where $A_{i}(t)$ is TFP, $g\left(H_{i}(t)\right)$ is the innovation component of TFP which depends on the level of education in country $i$ and the term $c\left(H_{i}(t)\right)\left(\frac{A_{m}(t)}{A_{i}(t)}-1\right)$ represents the rate of technology diffusion from the leader $m$ to country $i, g($.$) and c($.) being increasing functions.

Benhabib and Spiegel (2005) altered this framework to introduce the possibility of economic divergence in those cases in which some incompatibilities, impediments and barriers such as property rights moderate the diffusion of technology. To that end, the term $\left(A_{i} / A_{m}\right)$ is added, to represent the inverse of the distance to the frontier. This term dampens the rate of diffusion as the distance to the leader increases reflecting the difficulty of adopting distant technologies.

$$
\frac{\dot{A}_{i}(t)}{A_{i}(t)}=g\left(H_{i}(t)\right)+c\left(H_{i}(t)\right)\left(1-\frac{A_{i}(t)}{A_{m}(t)}\right)=g\left(H_{i}(t)\right)+c\left(H_{i}(t)\right)\left(\frac{A_{i}(t)}{A_{m}(t)}\right)\left(\frac{A_{m}(t)}{A_{i}(t)}-1\right),
$$

where $A_{i}(t)$ is TFP, $g\left(H_{i}(t)\right)$ is the innovation component of TFPG that depends on the level of education in country $i$ and the term $c\left(H_{i}(t)\right)\left(\frac{A_{i}(t)}{A_{m}(t)}\right)\left(\frac{A_{m}(t)}{A_{i}(t)}-1\right)$ represents the rate of technology diffusion from the leader to the country $i$.

In this specification, diffusion is moderated by "backwardness", and therefore catch-up may be slower when the country is very near to or very far from the technological frontier. The authors test this specification on a cross-section of 84 countries from 1960 to 1995 and only obtain robust evidence in favour of the imitation effect of human capital. With these results in mind, our work analyses the differences in the generation of new knowledge observable among different groups of countries inside the EU.

\section{The Estimation of the Logistic diffusion Model}

\subsection{Econometric specification}

As indicated above, we firstly test a model in the spirit of that proposed by Benhabib and Spiegel (2005). The empirical version of the model described in (2) is given by 


$$
\Delta a_{i t}=g h_{i t-3}+c h_{i t-3}\left[\frac{A_{t}^{\max }-A_{i t}}{A_{i t}}\right]\left[\frac{A_{i t}}{A_{t}^{\max }}\right]=(g+c) h_{i t-3}-c h_{i t-3}\left[\frac{A_{i t}}{A_{t}^{\max }}\right]+e_{i t}
$$

In this equation, $\Delta a_{i t}$ is the growth of total factor productivity, $h$ is the log of the human capital variable [measured as the average years of schooling using the data available in Penn World Table 8.0 (PWT 8.0)], $a$ is total factor productivity, and subscripts $i$, $t$ and max denote country, time and country leader, respectively. Human capital literature assumes that the effect of human capital on economic growth will take some time to be effective. To estimate this model, we have available annual information about this variable. In our first estimations, the first two lags of human capital showed a non-significant coefficient, and as a result the variable is included in the model with the third lag, the first to prove significant. Thus, the coefficients to be estimated are the direct effect of human capital on technical change $(g+c)$ and the rate of catch-up $(-c)$.

In this equation, the net effect of human capital on technological progress depends on how far a country is from the frontier and corresponds to the expression $\left[(g+c)-c \frac{A_{i}}{A^{\max }}\right]$. Consequently, the net effect of human capital on TFP for the leader is only the domestic innovation effect $(g)$.

Our model is a dynamic panel data model in which there are arbitrarily distributed fixed effects and current realisations of the dependent variable are influenced by past ones generating the "dynamic panel bias". This means that at least one regressor, the lagged endogenous variable, is correlated with the error, violating an assumption necessary for the consistency of Ordinary Least Squares (OLS). It inflates the coefficient estimated for the lagged endogenous variable by attributing predictive power to it that actually belongs to the country's fixed effect. Additionally, the relationship between human capital and TFPG is likely to be simultaneous and affected by reverse causality meaning endogeneity is a question needing to be addressed in this context. With this kind of data, considerable persistence is allowed for. To overcome these problems, we treat all right-hand side variables as endogenous. The estimation method is Instrumental Variables and our instruments are such right-hand side variables, lagged by one period ${ }^{1}$. We applied the Hausman test to decide between random versus fixed effects estimators.

Our estimation is based on Barcenilla and López-Pueyo (2018) where the logistic diffusion model (3) was estimated for EU countries. Here, we are interested in studying differences in TFP dynamics among different groups of countries inside the European Union. Firstly, we distinguish between euro and non-euro area countries and estimate Equation 3 for each such group. Secondly, we calculate the average income per capita in the EU along 1995-2013 and split the sample into two groups: those which have an average per capita income above this value, which represents countries very near to the frontier, and those which display a value under the EU average. Using the data offered in PWT 8.0 the average

The choice of lagging only once is made because it permits us to eliminate as much endogeneity as possible and maintain a reasonable number of observations. 
income per capita for 1995-2013 measured in constant 2005 US dollars is $\$ 27,791$. We term the countries that have a value over this mean Higher Average Income Countries (HAIC); these are Austria, Belgium, Denmark, Germany, Finland, France, the United Kingdom, Ireland, Italy, Luxembourg, the Netherlands and Sweden. The remaining EU countries comprise the Lower Average Income Countries (LAIC) group.

\subsection{Data}

The sample consists of a data panel from the twenty-eight EU countries for the years 1950-2011. The TFP level, TFPG and human capital variables are taken from Penn World Table. For the first time, the PWT 8.0 offers data on TFP that can be used for comparing TFP levels across countries and for comparing TFPG over time.

\section{Total Factor Productivity Growth}

Growth in TFP is defined as the logarithmic difference between the TFP of country $i$ in year $t$ and that of the previous period:

$$
\ln A_{i t}-\ln A_{i t-1} .
$$

To calculate TFPG we use a measure of productivity suitable for comparisons within a country over time, defined as:

$$
A_{i t} \equiv \frac{G D P_{t}^{N A}}{G D P_{t-1}^{N A}} / Q_{i t-1}^{T},
$$

where $G D P_{t}^{N A}$ is real GDP at constant national prices from PWT 8.0 and $Q_{i t-1}^{T}$ is the Törnqvist quantity index of factor inputs which compares inputs between $t-1$ and $t$ for a given country.

\section{Closeness to the frontier}

This variable is defined as the quotient between TFP in country $i$ and that of the leader.

$$
\frac{A_{i}}{A_{\max }} .
$$

Closeness is measured by the measure of TFPG, available in PWT 8.0, which is best suited to compare productivity between countries at one moment in time:

$$
\frac{A_{i}}{A_{\max }} \equiv \frac{G D P_{i}^{o}}{G D P_{j}^{o}} / Q_{i j}^{T},
$$

being $G D P_{i}^{o}$ the measure of the real GDP of country $i$ in PWT 8.0 and $Q_{i j}{ }^{T}$ a Törnqvist quantity index of factor inputs. In the empirical implementation PWT uses the US as 
the base country, and thus all countries are compared to $j=U S A$. For this reason, in our sample, there are some countries with a TFP level above the frontier. In this way, the results are similar to those obtained in experiments with a multilateral input index.

\section{Human capital}

PWT 8.0 introduces, for the first time, a measure of human capital which applies a rate of return based on Psacharopoulos (1994) to the average years of schooling of Barro and Lee $(2013)^{2}$. This index is based on a Mincerian transformation of the average years of schooling. The indicator has the important advantage of being comparable across countries and over time. It calculates the human capital $h c$ of country $i$ at time $t$ as a function of the average years of schooling $s$ :

$$
h c_{i t}=e^{\phi\left(s_{i t}\right)}
$$

where $\phi(s)$ are the Mincerian rates of return to education defined by Psacharopoulos (1994).

\subsection{Results}

The results of estimating Equation 3 are presented in Table 1. Our analysis starts with a regression in which only euro area countries are included. It has been estimated using a fixed effects instrumental variable estimation method, according to the results obtained from the Hausman test.

The coefficient for human capital $(g+c)$ is consistent with the idea of human capital as a facilitator of innovation and diffusion. The coefficient of the catch-up term $(-c)$ shows that human capital drives technology diffusion and that, for a given level of human capital, a greater distance to the frontier is associated with a greater increase in TFP.

The two coefficients estimated in Equation 3 are significant. The estimated coeffi-cient for human capital 0.0228 is positive and significant (at the $10 \%$ level) and the interaction of closeness to the frontier and education -0.0731 is also significant (at the $1 \%$ level $)^{3}$.

The principal novelty when we restrict the sample to non-euro area countries is the magnitude and significance of the coefficient $(g+c)$. It takes a value of 0.1277 , over five times higher than that obtained for euro area countries, and is significant at the $1 \%$ level. The coefficient $(-c)$, takes a value of -0.0928 and is significant at the $5 \%$ level.

$2 \quad$ See Feenstra et al. (2013) and Inklaar and Timmer (2013).

3 The resulting estimates of the parameter $g$ for euro countries, HAIC and LAIC countries are negative. This would be disappointing if we wanted to calculate a threshold value of human capital, below which catch up in total factor productivity could not occur. But this is not our purpose. It is also important to keep in mind that, given the decomposition techniques that we will carry out, the signs will not affect the results obtained in the decompositions. 
Table 1 | Total Factor Productivity Growth Equations, Logistic Diffusion Model of BS (2005)

\begin{tabular}{|c|c|c|c|c|}
\hline & \multicolumn{2}{|c|}{ Euro versus non-Euro Area } & \multicolumn{2}{|c|}{ HAIC versus LAIC } \\
\hline & $\begin{array}{c}\text { Euro } \\
(1)\end{array}$ & $\begin{array}{l}\text { Non-Euro } \\
\text { (2) }\end{array}$ & $\begin{array}{l}\text { HAIC } \\
\text { (3) }\end{array}$ & $\begin{array}{l}\text { LAIC } \\
\text { (4) }\end{array}$ \\
\hline$h_{i t-3}$ & $\begin{array}{l}0.0228^{*} \\
(0.0144)\end{array}$ & $\begin{array}{l}0.1277^{* * *} \\
(0.0508)\end{array}$ & $\begin{array}{l}0.0127^{*} \\
(0.0088)\end{array}$ & $\begin{array}{l}0.0960^{* * *} \\
(0.0316)\end{array}$ \\
\hline$h_{i t-3}\left(\frac{A_{i t}}{A_{t}^{\max }}\right)$ & $\begin{array}{l}-0.0731^{* * *} \\
(0.1092)\end{array}$ & $\begin{array}{l}-0.0928^{* * *} \\
(0.0294)\end{array}$ & $\begin{array}{l}-0.0422^{* * *} \\
(0.0064)\end{array}$ & $\begin{array}{c}-0.1564^{* * *} \\
(0.0261)\end{array}$ \\
\hline Sample size & 861 & 344 & 529 & 676 \\
\hline Number of countries & 19 & 9 & 16 & 12 \\
\hline Hausman test & $\begin{array}{l}20.58 \\
(0.00)\end{array}$ & $\begin{array}{c}7.74 \\
(0.02)\end{array}$ & $\begin{array}{l}3.31 \\
(0.19)\end{array}$ & $\begin{array}{l}18.90 \\
(0.00)\end{array}$ \\
\hline Panel model & Fixed & Fixed & Random & Fixed \\
\hline $\mathbf{R 2}$ & 0.1373 & 0.0198 & 0.1259 & 0.1105 \\
\hline $\begin{array}{l}\text { Prediction of TFPG } \\
\text { rates }\end{array}$ & $\begin{array}{l}0.0116^{* * *} \\
(0.0011)\end{array}$ & $\begin{array}{l}0.0087^{* * *} \\
(0.0019)\end{array}$ & $\begin{array}{l}0.0082^{* * *} \\
(0.0009)\end{array}$ & $\begin{array}{l}0.0140^{* * *} \\
(0.0019)\end{array}$ \\
\hline $\begin{array}{l}\text { Differential } \\
\text { prediction in TFPG } \\
\text { rates }\end{array}$ & \multicolumn{2}{|c|}{$\begin{array}{l}-0.0028 \\
(0.0022)\end{array}$} & \multicolumn{2}{|c|}{$\begin{array}{l}0.0057^{* * *} \\
(0.0021)\end{array}$} \\
\hline
\end{tabular}

Note: In parentheses there are the corrected standard errors of the coefficients where ${ }^{* * *},{ }^{* *}$ and ${ }^{*}$ denote the 1,5 and $10 \%$ level of significance respectively, according to the t-statistic.

Source: Own calculations based on PWT 8.0

Nevertheless, when we analyse the magnitude of the differences in TFPG between euro and non-euro countries (final row of Table 1) we can see that these differences are not significant. This means that the institutional division between euro and non-euro countries does not display significant differences in TFPG. On the contrary, the distinction between HAIC and LAIC generates differences in productivity dynamics that are significant at the $1 \%$ level.

As Column 3 of Table 1 shows, in the case of HAIC we selected a random effects instrumental variable model according to the results of the Hausman test. Qualitatively, the estimation of the logistic diffusion model for HAIC gives the same result as previous estimations. The coefficient for the human capital variable, 0.0127 , is positive and significant (at the $10 \%$ level), while the coefficient of the interaction term 0.0422 is negative and also significant at the $1 \%$ level. For LAIC, the fixed effects estimation shows that the coefficient of the two variables is also significant and greater than those obtained for HAIC. In this case, the value of $(g+c) 0.096$ is eight times greater than the same coefficient in the HAIC subsample, while the value of $(-c)-0.1564$ is over three times higher. Furthermore, the significance of the first coefficient is superior ( $1 \%$ versus $10 \%)$ in LAIC. 
The constant is only statistically significant in HAIC. This term could be interpreted as exogenous technological progress, independent of human capital and technology diffusion.

Consequently, the last two models and the differences in TFPG observed among the subsamples which they are based on will be the starting point of our Shorrocks-Shapley and Oaxaca-Blinder decompositions analysis.

\section{The Causes of Differences in Total Factor Productivity Growth among European Union Country Groups}

\subsection{Shorrocks-Shapley decomposition}

As seen above, differences in technical change among countries can be seen due to differences in human capital (direct effect) or differences in catch-up capacity. The ShorrocksShapley decomposition (SSD) provides a useful instrument to discompose the goodness of fit (R-square-overall) of model (3) and so to determine the relative contribution of each factor. The method is based on the calculation of the variance for all possible permutations of the regressors of the model (Shorrocks, 1982). The methodology has important advantages compared with other decompositions, as it satisfies the axioms of 1) efficiency: the goodness of fit of the model is decomposed among the explanatory variables; 2) monotonicity: the increase in R-square-overall must not decrease the value of each component; and 3) equal treatment: perfect substitutes in terms of the goodness of fit receive the same value (Huettner and Sunder, 2012).

Table 2 | Shorrocks-Shapley Decomposition of Total Factor Productivity Growth

\begin{tabular}{|c|c|c|c|c|c|c|c|c|c|c|}
\hline \multirow[t]{2}{*}{ Factor } & \multicolumn{2}{|c|}{ Whole sample } & \multicolumn{2}{|c|}{ Euro } & \multicolumn{2}{|c|}{ Non-Euro } & \multicolumn{2}{|c|}{ HAIC } & \multicolumn{2}{|c|}{ LAIC } \\
\hline & $\begin{array}{c}\text { Shapley } \\
\text { value }\end{array}$ & $\begin{array}{c}\text { Per cent } \\
\text { (\%) }\end{array}$ & $\begin{array}{c}\text { Shapley } \\
\text { value }\end{array}$ & $\begin{array}{c}\text { Per cent } \\
\text { (\%) }\end{array}$ & $\begin{array}{c}\text { Shapley } \\
\text { value }\end{array}$ & $\begin{array}{c}\text { Per cent } \\
\text { (\%) }\end{array}$ & $\begin{array}{c}\text { Shapley } \\
\text { value }\end{array}$ & $\begin{array}{c}\text { Per cent } \\
\text { (\%) }\end{array}$ & $\begin{array}{c}\text { Shapley } \\
\text { value }\end{array}$ & $\begin{array}{c}\text { Per cent } \\
\text { (\%) }\end{array}$ \\
\hline $\begin{array}{l}\text { Human } \\
\text { capital }\end{array}$ & 0.0114 & 14.52 & 0.0215 & 15.85 & 0.0002 & 3.52 & 0.0305 & 26.05 & 0.0084 & 12.82 \\
\hline $\begin{array}{l}\text { Catch up } \\
\text { capacity }\end{array}$ & 0.0669 & 85.48 & 0.1140 & 84.15 & 0.0051 & 96.56 & 0.0865 & 73.95 & 0.0574 & 87.18 \\
\hline $\begin{array}{l}\text { Propor- } \\
\text { tions }\end{array}$ & & & & & & & & & & \\
\hline $\begin{array}{l}\text { R-sq } \\
\text { overall }\end{array}$ & 0.0783 & 100.00 & 0.1345 & 100.00 & 0.0052 & 100.00 & 0.1169 & 100.00 & 0.0358 & 100.00 \\
\hline Obs. & 12 & 05 & & 61 & & 44 & 67 & 76 & 52 & 29 \\
\hline Countries & & 8 & & 8 & & 9 & 1 & 2 & 1 & 6 \\
\hline
\end{tabular}

Notes: 2SLS estimation. Instruments: lag of innovation and imitation. Fixed effects for countries. Estimates performed with the Shapley 2 Stata command developed by Chávez Juárez (2012).

Source: Own calculations based on PWT 8.0 
Despite these advantages, it must be borne in mind that explanatory variables in the present model may not be exogenous, in the econometric sense that its components could be correlated with other unobserved variables. Consequently, individual elements of the vector suffer from these omitted variable biases. While this does not affect the estimation of the variance, the decomposition components should not be interpreted as accurate causal estimates of the individual impact of a specific factor on the dependent variable. Thus, they only give an idea of their relative importance (Ferreira and Gignoux, 2014).

Table 2 presents the SSD for our whole sample and the subsamples. Between 0.0052 and 0.1354 of all the heterogeneity in the technical change can be explained by human capital and catch-up capacity. The results are presented both in levels and as a percentage of the total variance. As can be seen, the most important explanatory factor is catch-up capacity, which accounts in every case for the majority of the R-square-overall $(85.48 \%$ of the variance in the whole sample versus $14.52 \%$ of the human capital). This catch-up effect is more important for non-euro countries than for euro countries $(96.56 \%$ of the variance versus $84.15 \%$ ), and for LAIC than for HAIC (87.18\% versus $73.95 \%)$.

Our results are in line with those of Vandenbussche, Aghion and Meghir (2006), Aghion et al. (2006), Aghion, Howitt and Bursztyn (2009) and Islam (2010). These studies relate the processes of innovation and assimilation of foreign technologies to the degree of development of economies. On the one hand, the human capital effect is linked to the innovation capacity of countries. On the other hand, the catch-up effect is linked to their capacity for convergence through assimilation and imitation. Both processes play a key role in growth. The farther countries are from the technological frontier, the more important the processes of assimilation and imitation will be for growth. The closer the countries are to the technological frontier, the more important will be the innovation processes. For all these reasons, it is clear that innovation policies based on the accumulation of highly skilled human capital are particularly important in the case of the most developed economies in order to compete in the global market. López-Pueyo et al. (2017) highlight that, as these economies have little scope for increasing their average years of schooling, innovationeffective education policies should focus not only on increasing school attainment, but also on enhancing cognitive skills.

\subsection{Oaxaca-Blinder decomposition}

The Oaxaca-Blinder decomposition $(\mathrm{OBD})^{4}$ is a suitable methodology to understand the differences in the result achieved by two groups of individuals; Jann (2008) explains this methodology thoroughly. In our case, the interest lies in understanding the causes of the differences in technological change between two groups of countries. As we have pointed out, Table 1 shows that the differences in the predicted value of the model in TFPG between euro and non-euro countries are not significant. Consequently, it makes no

$4 \quad$ This methodology was developed in the seminal papers of Oaxaca (1973) and Blinder (1973) and is used mostly in labour economics to study the causes of wage gaps. However, despite its potential, its penetration into other fields of economics and other social sciences has been much lower. 
statistical sense to perform the OBD on these subsamples. For this reason, our analysis will focus on the explanation of the differences in TFPG between HAIC and LAIC, the latter being the reference group for the OBD.

To decompose the difference in technical change between the two groups we calculate two regressions, one for each group. From these regressions, we can obtain two components:

1. The observed component, which accounts for the differences in the average input endowments of the members of each group. This component is calculated as the difference in technical change LAIC would attain if they had the same endowments as HAIC.

2. The unobserved component has a residual character. This component demonstrates the part of the variance of the results that is not explained by the model (endowments). Consequently, it includes all the omitted relevant characteristics. It can be decomposed into two effects:

2.1. The coefficients effect accounts for the differences in the coefficients, including the intercept. It is calculated as the difference in the technical change that LAIC would have if they obtained the same coefficients as HAIC.

2.2. The other effect is an interaction term which accounts for the fact that the differences, both in endowments and coefficients, occur simultaneously in LAIC and HAIC.

The difference (D) in the predicted values of the technical change for each group can be expressed as:

$$
\begin{aligned}
D= & E\left(\text { TechnicalChange }_{\text {LAIC }}\right)-E\left(\text { TechnicalChange }_{\text {HAIC }}\right)= \\
& \underbrace{\left\{\begin{array}{l}
\left.E\left(\boldsymbol{X}_{\text {LAIC }}\right)-E\left(\boldsymbol{X}_{\text {HAIC }}\right)\right\}^{\prime} \boldsymbol{\beta}_{\text {LAIC }} \\
\text { Endowments effect }
\end{array}\right.}_{\text {Observed component }} \\
& +\underbrace{\underbrace{E\left(\boldsymbol{X}_{\text {LAC }}\right)^{\prime}\left(\boldsymbol{\beta}_{\text {LAIC }}-\boldsymbol{\beta}_{\text {HAIC }}\right)}_{\text {Coefficients effect }}+\underbrace{\left\{E\left(\boldsymbol{X}_{\text {LAIC }}\right)-E\left(\boldsymbol{X}_{\text {HAIC }}\right)\right\}^{\prime}\left(\boldsymbol{\beta}_{\text {LAIC }}-\boldsymbol{\beta}_{\text {HAIC }}\right)}_{\text {Interaction effect }}}_{\text {Unobserved component }}
\end{aligned}
$$

being $\boldsymbol{X}$ the vector of endowments, which groups together the variables that explain technical change, and $\boldsymbol{\beta}$ the vector of coefficients, including the intercept.

It is important to note that the OBD methodology will suffer from the same estimation problems as the original model we are working with. The more efficient the estimator used, the more efficient is the resulting decomposition. In this context, the decomposition is made using the Arellano and Bond estimator with the variables lagged as instruments.

Table 3 shows that, according to the OBD, the difference in the estimated value of the knowledge production function between the two groups of countries is statistically significant. The estimated difference between the average annual technical change produced in the LAIC and the HAIC group is 0.0057 ( 0.57 percentage points): the mean predicted technical change in LAIC is $1.4 \%$, while in the HAIC it is $0.83 \%$. 
The mean difference in technical change that would result if LAIC had, the same human capital and catch-up capacity as HAIC is 0.0378 (endowments effect). The expected change in the difference in technical change that LAIC would experience if they had on average the same returns to human capital and catch-up capacity as HAIC is -0.0044 (coefficients effect). Finally, the interaction effect is -0.0277 . From these effects, we can deduce that the part of the difference explained by the model and which is due to differences in endowments, accounts for $54 \%$, versus $46 \%$ for the unobserved component.

Table 3 | Oaxaca-Blinder Decomposition Detailed Results

\begin{tabular}{|c|c|c|}
\hline & LAIC & HAIC \\
\hline Prediction of TFPG rates & $\begin{array}{l}0.0140^{* * *} \\
(0.0019)\end{array}$ & $\begin{array}{l}0.0082^{* * * *} \\
(0.0009)\end{array}$ \\
\hline Differential prediction in TFPG rates & \multicolumn{2}{|c|}{$\begin{array}{c}0.0057^{* * *} \\
(0.0021)\end{array}$} \\
\hline \multicolumn{3}{|l|}{ Endowments } \\
\hline Human capital & \multicolumn{2}{|c|}{$\begin{array}{c}0.0006 \\
(0.0010)\end{array}$} \\
\hline Catch-up capacity & \multicolumn{2}{|c|}{$\begin{array}{l}0.0372^{* * *} \\
(0.0064)\end{array}$} \\
\hline Total & \multicolumn{2}{|c|}{$\begin{array}{l}0.0378 * * * \\
(0.0065)\end{array}$} \\
\hline \multicolumn{3}{|l|}{ Coefficients } \\
\hline Human capital & \multicolumn{2}{|c|}{$\begin{array}{l}0.0772^{* * *} \\
(0.0304)\end{array}$} \\
\hline Catch-up capacity & \multicolumn{2}{|c|}{$\begin{array}{l}-0.0673^{* * *} \\
(0.0159)\end{array}$} \\
\hline Constant & \multicolumn{2}{|c|}{$\begin{array}{l}-0.0142 \\
(0.0173)\end{array}$} \\
\hline Total & \multicolumn{2}{|c|}{$\begin{array}{c}-0.0044^{* *} \\
(0.0025)\end{array}$} \\
\hline \multicolumn{3}{|l|}{ Interaction } \\
\hline Human capital & \multicolumn{2}{|c|}{$\begin{array}{c}0.0005 \\
(0.0009)\end{array}$} \\
\hline Catch-up capacity & \multicolumn{2}{|c|}{$\begin{array}{l}-0.0271^{* * *} \\
(0.0065)\end{array}$} \\
\hline Total & \multicolumn{2}{|c|}{$\begin{array}{l}-0.0277^{* * *} \\
(0.0066)\end{array}$} \\
\hline
\end{tabular}

Notes: Panel IV estimates performed with the Oaxaca Stata command developed by Jann (2008). The first lag of the independent variables is used as an instrument.

Source: Own calculations based on PWT 8.0 
When we examine more closely the differences caused by the endowments, we see that human capital and catch-up capacity $\left(\log \mathrm{KH}^{*} A_{i} / A_{\max }\right)$ have positive signs, and thus they both widen the differences in technical change. This can be interpreted as that the endowments of both factors favour LAIC. The element that helps most to explain the differences in technical change is catch-up capacity (0.0372).

As Table 4 shows, the human capital endowment in the two groups is similar $(\operatorname{logKH}$ $\mathrm{LAIC}=0.9267$ and $\operatorname{logKH} \mathrm{HAIC}=0.9197)$. The difference is explained mainly by the largest mean distance of the LAIC (the variable $A_{i} / A_{\max } \mathrm{LAIC}=0.6407$ and $A_{i} / A_{\max } \mathrm{HAIC}=$ 0.8919). This means that the catch-up capacity favours LAIC. The difference of 0.0372 in the TFPG between LAIC and HAIC is explained by the difference in the average catch-up capacity in both country groups and, within this, principally by the difference in the average distance to the leader.

Table 4 | Means of the Variables

\begin{tabular}{|l|c|c|}
\hline & LAIC & HAIC \\
\hline Human capital & 0.9267 & 0.9197 \\
\hline Catch-up capacity & 0.5898 & 0.8276 \\
\hline Proximity to the frontier & 0.6407 & 0.8919 \\
\hline
\end{tabular}

Source: Own calculations based on PWT 8.0

Regarding the use of these endowments, the decomposition of the coefficient effects, in Table 3, shows that LAIC use their human capital endowments more efficiently (0.0772). This contributes to increasing the differences in technical change. By contrast, the catch-up capacity has a negative sign $(-0.0673)$ meaning that proximity decelerates more technical change in LAIC, thereby reducing the differences in technical change between the two country groups.

Finally, we can see in Table 3 how the interaction effect of catch-up capacity $(-0.0277)$ also contributes to reducing the differences in TFPG. In this case, the human capital effect is almost insignificant $(0.0005)$.

To summarise, the mean difference in technical change between LAIC and HAIC is largely the result of three factors. The first is the higher average foreign technology assimilation capacity of LAIC. This is particularly true because they are further from the technological frontier and are able to benefit from the advantage of backwardness. The second reason is the higher direct effect of human capital on technical change in these countries, while the third factor is that proximity decelerates more technical change in LAIC.

As far as we know, this is for the first time that this kind of decompositions are applied to the study of Total Factor Productivity Growth. So, we cannot specifically compare the results obtained with other studies. However, our analysis confirms the importance that adoption of foreign technologies and investment in human capital have in terms 
of innovation for middle income countries. Newly industrialized countries can assimilate technologies developed in leading countries and adapt them to become next round innovators. But this assimilation of foreign technologies can be more complicated and costly than it may seem at first sight and requires a well-educated workforce. These ideas are confirmed empirically by Mansfield, Schwartz and Wagner (1981), Levin et al. (1987), Harabi (1991), Mukoyama (2003) and Baumol (2004). In the words of Nelson (2007, p.11), "as the [technological and economic] frontier is approached, the lines between sophisticated imitation and creative design of new products and processes become blurry".

\section{Conclusions}

The importance of human capital for understanding the generation of technical change and economic growth has been widely recognised in recent literature on economic growth. Our results show that human capital has a doubly positive effect on economic growth by boosting innovation and by increasing the capacity of countries to absorb foreign technologies. These positive effects exist in different groups of euro versus non-euro area countries and HAIC versus LAIC. The analysis of the differences in the means of technical change between these groups gives rise to three main insights.

Firstly, differences in the intensity of these effects are only statistically significant in LAIC versus HAIC and, thus, we can conclude that monetary union does not cause differential behaviour in the way and the magnitude with which human capital affects technological change and, subsequently, economic growth. On the contrary, there is a significant difference between those countries which have had an above average level of per capita income in the last two decades, which can be considered as the leaders in this context of developed countries, and those which have not.

Secondly, differences in the magnitude of the endowments are much less important than differences in the effects or returns of these endowments in the context of European Union countries. LAIC are those that most enjoy an increase in human capital, because they have higher average returns to human capital in technical change, through both direct effects and foreign technology assimilation.

Why are some countries more efficient in using human capital in knowledge production? We may speculate about the reasons behind the higher direct return of human capital and the improved use of assimilation capacity in LAIC. A first such reason could be, as Manca (2011) states, the average endowment of other factors such as physical capital or institutions which are more welcoming for knowledge production. In this regard, it is possible to find countries with more suitable institutions for innovation or for the assimilation of foreign technologies.

A second type of reasons could be those related to the measurement of human capital. Specifically, there has been considerable criticism of the measurement of human capital which considers only quantitative issues, as our PWT variable does. If qualitative issues, such as cognitive skills, were taken into account in the human capital variable, the country ranking in terms of this new variable could be different, as could the results for the estimation of returns. That is, if only quantitative measures to proxy human capital 
are considered, we may under- or overestimate the contribution of human capital to technical change. This is an important issue to incorporate into further research.

Finally, the mean difference in technical change between LAIC and HAIC is also due to the higher average foreign technology assimilation capacity in LAIC. This is specifically explained because they are further from the technological frontier, and are therefore able to benefit from the advantage of backwardness.

From a political point of view, it is necessary to reflect the measurement of human capital that has been considered in our study. It is a measure of average years of study, adjusted by Mincerian rates of return. Consequently, it can be concluded that education, in its widest sense, matters in Europe not only for imitation but also for innovation. Nevertheless, the magnitude and the effect of this kind of human capital in facilitating the adoption of foreign technologies are much clearer than in innovation. Consequently, our results suggest that highly skilled human capital is necessary for growth by innovation, as the recent paper by Barcenilla and López-Pueyo (2018) has demonstrated. Such a conclusion is in line with the dominant academic proposals regarding education and growth, which also underline the importance of designing appropriate policies and institutions to promote innovation and imitation in each stage of development. As the model predicts, distance to the frontier will diminish and subsequently the advantage in assimilation capacity for LAIC will be eroded. This means that in the future human capital will have to be reallocated from imitation to innovation and institutions will have to be reorganised to stimulate this latter activity.

\section{References}

Aghion, P., Boustan, L., Hoxby, C., Vandenbussche, J. (2006). Exploiting States' Mistakes to Identify the Causal Impact of Higher Education on Growth. ISNIE Conference Paper.

Aghion, P., Howitt, P., Bursztyn, L. (2009). The Economics of Growth. Cambridge, Mass: MIT Press.

Arellano, M., Bover, O. (1995). Another Look at the Instrumental Variable Estimation of ErrorComponents Models. Journal of Econometrics, 68(1), 29-52, https://doi. org/10.1016/0304-4076(94)01642-d

Barcenilla, S., López-Pueyo, C. (2018). Inside Europe: Human Capital and Economic Growth Revisited. Empirica, On-line first DOI 10.1007/s10663-017-9394-2.

Barro, R., Lee, J. W. (2013). A New Data Set of Educational Attainment in the World, 19502010. Journal of Development Economics, 104, 184-198, https://doi.org/10.1016/j. jdeveco.2012.10.001

Baumol, W. J. (2004). Difusión y adaptación de la tecnología: El crecimiento a través de la innovación imitativa. Información Comercial Española, 814, 5-16.

Benhabib, J., Spiegel, M. M. (1994). The Role of Human Capital in Economic Development Evidence from Aggregate Cross-Country Data. Journal of Monetary Economics, 34(2), 143-173, https://doi.org/10.1016/0304-3932(94)90047-7

Benhabib, J., Spiegel, M. M. (2005). Human Capital and Technology Diffusion, in Aghion, P., Durlauf, S. N., eds., Handbook of Economic Growth, 1 A. Amsterdam and San Diego: NorthHolland, 935-966.

Blinder, A S. (1973). Wage Discrimination: Reduced Form and Structural Estimates. Journal of Human Resources, 8(4), 436-455, https://doi.org/10.2307/144855 
Cerina, F., Manca, F. (2012). Catch Me if You Learn: Development-Specific Education and Economic Growth. Centre for North South Economic Research, University of Cagliari and Sassari. Sardinia Working Paper CRENoS 201225.

Chavez Juarez, F. (2012). SHAPLEY2: Stata Module to Compute Additive

Decomposition of Estimation Statistics by Regressors or Groups of Regressors. Statistical Software Components S457543, Boston College Department of Economics, revised 17 June 2015.

Feenstra, R. C., Inklaar, R., Timmer, M. P. (2013). The Next Generation of the Penn World Table. NBER. Working Paper No. 19255, https://doi.org/10.3386/w19255

Ferreira, F., Gignoux, J. (2014). The Measurement of Educational Inequality: Achievement and Opportunity. World Bank Economic Review, 28(2), 210-246, https://doi.org/10.1093/wber/ Iht004

Ha, J., Howitt, P. (2007). Accounting for Trends in Productivity and R\&D: A Schumpeterian Critique of Semi-Endogenous Growth Theory. Journal of Money, Credit and Banking, 39(4), 733-774, https://doi.org/10.1111/j.1538-4616.2007.00045.x

Harabi, N. (1991). Innovation versus Imitation: Empirical Evidence from Swiss Firms. Munich Personal RePEc Archive MPRA, No. 26214.

Howitt, P., Mayer-Foulkes, D. (2005). R\&D, Implementation, and Stagnation: A Schumpeterian Theory of Convergence Clubs. Journal of Money, Credit and Banking, Blackwell Publishing, 37(1), 147-177, https://doi.org/10.1353/mcb.2005.0006

Huettner, F., Sunder, M. (2012). Axiomatic Arguments for Decomposing Goodness of Fit according to Shapley and Owen Values. Electronic Journal of Statistics, 6, 1239-1250, https://doi.org/10.1214/12-ejs710

Inklaar, R., Timmer, M. P. (2013). Capital, Labour and TFP in PWT8.0. Groningen Growth and Development Centre. University of Groningen Working Paper.

Islam, M. R. (2010). Human Capital Composition, Proximity to Technology Frontier and Productivity Growth. Monash Economics Working Papers, No. 23-10.

Jann, B. (2008). The Blinder-Oaxaca Decomposition for Linear Regression Models. Stata Journal, 8(4), 453-479.

Levin, R. C., Klevorick, A. K., Nelson, R. R., Winter, S. G., Gilbert, R., Griliches, Z. (1987). Appropriating the Returns from Industrial Research and Development. Brookings Papers on Economic Activity, 3 Special Issue on Microeconomics, 783-821, https://doi. org/10.2307/2534454

López-Pueyo, C., Barcenilla, S., Giménez, G. (2018). The Two Faces of Human Capital and their Effect on Technological Progress, Panoeconomicus, 65(2),163-181, https://doi.org/10.2298/ PAN151002014L.

Manca, F. (2011). The Farthest Need the Best. Human Capital Composition and Developmentspecific Economic Growth. IREA-Working Papers, 2011, IR11/017.

Mansfield, E., Schwartz, M., Wagner, S. (1981). Imitation Costs and Patents: An Empirical Study. Economic Journal, 91(364), 907-918, https://doi.org/10.2307/2232499

Mukoyama, T., (2003). Innovation, Imitation, and Growth with Cumulative Technology. Journal of Monetary Economics, 50(2), 361-380, https://doi.org/10.1016/s0304-3932(03)00005-9

Nelson, R. R., Phelps, E. S. (1966). Investment in Humans, Technological Diffusion, and Economic Growth. The American Economic Review, 56(1-2), 69-75. 
Nelson, R. R. (2007). The Changing Institutional Requirements for Technological and Economic Catch Up. International Journal of Technological Learning, Innovation and Development, 1(1), 4-12, https://doi.org/10.1504/ijtlid.2007.015016

Oaxaca, R. L. (1973). Male-Female Wage Differentials in Urban Labor Markets. International Economic Review, 14(3), 693-709, https://doi.org/10.2307/2525981

Papakonstantinou, M. (2014). Composition of Human Capital, Distance to the Frontier and Productivity. Paper prepared for the IARIW 33rd General Conference Rotterdam, the Netherlands.

Romer, P. M. (1990). Endogenous Technological Change. Journal of Political Economy, 98(5), S71-102, https://doi.org/10.1086/261725

Shorrocks, A. (1982). Inequality Decomposition by Factor Components. Econometrica, 50(1), 193-211, https://doi.org/10.2307/1912537

Vandenbussche, J., Aghion, P., Meghir, C. (2006). Growth, Distance to Frontier and Composition of Human Capital. Journal of Economic Growth, 11(2), 97-127, https://doi. org/10.1007/s10887-006-9002-y 